\begin{tabular}{|c|l|}
\hline Title & Effect of a community of practice on knowledge sharing across boundaries: the mediating role of learning goals \\
\hline Author(s) & Matsuo, Makoto; A ihara, Motohiro \\
\hline Citation & $\begin{array}{l}\text { Journal of knowledge management } \\
\text { https://doi.org/L0.1108/1KM-08-2020-0604 }\end{array}$ \\
\hline Issue Date & 2022-01-18 \\
\hline Doc URL & http://hdl.handle.net/2115/83840 \\
\hline Type & article (author version) \\
\hline File Information & Self-archiving (JKM 2022) sub.pdf \\
\hline
\end{tabular}

Instructions for use 
Journal of Knowledge Management

Vol. 26, No. 1, pp. 1-16, 2022.

DOI: 10.1108/JKM-08-2020-0604

\title{
Effect of a community of practice on knowledge sharing across boundaries: the mediating role of learning goals
}

\author{
Makoto Matsuo and Motohiro Aihara \\ Graduate School of Economics and Business Administration, Hokkaido University, \\ Sapporo, Japan
}

\begin{abstract}
Purpose - A community of practice $(\mathrm{CoP})$ is believed to be a driver for knowledge creation but it can hinder knowledge sharing across boundaries. Drawing on social cognitive theory, this study aims to investigate how a $\mathrm{CoP}$ within a single unit promotes knowledge sharing with other units by examining the mediating effect of the members' learning goals (LG).

Design/methodology/approach - Structural equation modeling was conducted using a twowave survey data on nurses from eight Japanese hospitals $(n=263)$.

Findings - The results indicated that LG fully and positively mediated the effect of a CoP on the knowledge-sharing intention of one unit toward other units and that LG fully and negatively mediated the effect of a CoP on knowledge withholding $(\mathrm{KW})$ from other units.

Practical implications - Knowledge managers need to note that intellectual benefits from experienced CoP can play a key role in reducing the perceived risks associated with members' knowledge sharing and in creating effective knowledge sharing with other units.

Originality - The main contribution is to identify the process by which CoP promotes
\end{abstract}


knowledge sharing and prevents KW across boundaries mediated through LG. This study is the first to quantitatively show how LG cross inter-professional barriers caused by CoPs.

Keywords Knowledge sharing intention, Community of practice, Knowledge withholding, Learning goals

Paper type Research paper

\section{Introduction}

Knowledge sharing is considered a key component of knowledge management because it improves an organization's capabilities through individual learning (Kim, 2019). Among various kinds of antecedents, a community of practice $(\mathrm{CoP})$ has received widespread attention as a way to manage the creation and dissemination of knowledge within an organization (Ardichvili et al., 2006; Botelho, 2018; Brown and Duguid, 1991; Pyrko et al., 2019). According to Wenger et al. (2002), a CoP is a group of people who share a concern, set of problems, or passion about a topic and who deepen their knowledge and expertise in it by interacting on an ongoing basis. Furlong and Johnson (2003) viewed CoPs as meta-capabilities that contribute to developing the core competency of organizations by sharing knowledge and generating innovation. Thus, the creation of an effective $\mathrm{CoP}$ is one of the top priorities of knowledge management investment (Haas et al., 2020).

For example, health-care organizations often develop learning communities in which multi-disciplinary professionals collaborate to address issues such as "dementia" (Sheaff et al., 2018), "cancer screening and disparities" (Myers et al., 2018) and "HIV” (Barbosu et al., 2017). It is worth noticing that from 2014-2016 the Agency for Healthcare Research and Quality (AHRQ), i.e. the lead Federal agency charged with improving the safety and quality of America's health-care system, established learning communities on high-priority topics to 
support the adoption and spread of health-care innovations (AHRQ Health Care Innovations Exchange, 2016). Participants across organizations interactively worked together in group settings to adapt and tailor the strategies and solutions to their organizations' unique contexts under the support of experts (Agency for Healthcare Research and Quality, 2021). It was found that the learning community model can serve as an effective method to support sharing of innovative healthcare knowledge (Carpenter et al., 2018).

Previous research has mainly investigated how knowledge is shared within a CoP (Hara and Hew, 2007; Jeon et al., 2011; Tseng and Kuo, 2014; Wasko and Faraj, 2000); few studies have examined the knowledge-sharing process across CoPs and even fewer have used quantitative methods to do so. Individuals belong to multiple communities, which must create potential tensions and conflicts among them (Christensen and Pedersen, 2018; Handley et al., 2006; Hwang et al., 2015), as well as between a CoP and the bureaucracy (Harvey et al., 2013; Tsai, 2002). In particular, knowledge transfer and collaborative work tend to be hindered by inter-professional boundaries in pluralistic organizations such as hospitals (Powell and Davies, 2012; Tasselli, 2015). Liberati et al. (2016) call such disciplinary boundaries "invisible walls." Thus, community members may find it challenging to share knowledge across CoPs (Pan and Leidner, 2003). Exploring knowledge sharing across CoPs is, therefore, an important topic for knowledge-management research.

To address this research gap, we explored the following research question: how experienced CoPs within a single unit promote the intention of knowledge sharing intention and reduce knowledge withholding (KW) across boundaries? This study focused on $\mathrm{KW}$ because it is an intentional attempt to conceal knowledge that individuals could share (Tsay et al., 2014), whereas the sharing of less knowledge is often caused by an inability to share relevant knowledge owing to a lack of it (Kang, 2016). Notably, KW, defined as the likelihood of an individual giving less than full effort to contributing knowledge (Lin and Huang, 2010), 
can impede organizational learning capacity to transfer best practices and stimulate innovation (Haas and Park, 2010). Examining KW, which is not the antonym of "knowledge sharing", allowed this study to identify the process by which knowledge is shared and transferred across boundaries.

Our research draws on social cognitive theory (SCT), which assumes that the set of personal and contextual factors influence each other bidirectionally (Bandura, 1989, 2001, 2005; Wood and Bandura, 1989). Based on the theory, we proposed a model hypothesizing that through individuals' learning goals (LG), experienced CoP within a unit promotes knowledgesharing intention toward other units and limits KW from them (Figure 1). Specifically, we predicted that employees engaged in $\mathrm{CoP}$ within a unit are likely to share their knowledge instead of hiding it when they have higher LG.

Although LG have been shown to promote knowledge sharing (Kim and Lee, 2013; Lu et al., 2012; Matzler and Muller, 2011), little is known about the mediating role of LG in the relationship between CoPs and knowledge sharing intention. We assume that a CoP enhances its members' LG by stimulating their intellectual curiosity, through which they are motivated to share knowledge, based on their expectation of reciprocal knowledge exchange (Cabrera and Cabrera, 2005; Lu et al., 2012). The main contribution of this study to the literature on knowledge management is that it identifies the role of LG in linking a CoP to knowledge sharing across boundaries.

To investigate our research model, we analyzed data on nurses working in hospitals, for two reasons. First, the multiple CoPs operating in hospitals feature potential tensions and conflicts because health-care organizations comprise multi-disciplinary professional communities (Denis et al., 2001; Mørk et al., 2010; Oborn and Dawson, 2010). Second, nurses are considered to play important roles in facilitating interdisciplinary collaboration in healthcare systems (Bender et al., 2013). 
The remainder of this paper is organized as follows. First, we review the literature on knowledge sharing, KW, LG, and CoPs. Next, we describe the quantitative methodology used in this study. Then, we present the results of a two-wave survey of nurses in eight Japanese hospitals $(n=263)$. Finally, we discuss the results from both theoretical and practical perspectives.

\section{Theoretical background and hypotheses}

\section{Knowledge sharing and withholding}

By sharing their knowledge within an organization, employees can indirectly learn from the experience of others and that of other units (Argote and Miron-Spektor, 2011; Christensen and Pedersen, 2018). Cabrera and Cabrera (2005) suggested that knowledge sharing is necessary for a firm to achieve competitive advantages. Thus, investigating the mechanisms of how knowledge is effectively shared within an organization is a significant research topic (Hansen et al., 2005). Based on a literature review, Ipe (2003) stated that knowledge sharing in organizations is influenced by the nature of knowledge, employees' motivation and opportunities to share, and the culture of the work environment.

Drawing on Fishbein and Ajzen's (1975) theory of reasoned action, Bock et al. (2005) verified a model in which behavioral intention to share knowledge was influenced by attitude toward knowledge sharing, subjective norms and organizational climate. They focused on knowledge-sharing intention, that is, the willingness of individuals to share their knowledge with others in an organization because it determines an individual's decision to engage in knowledge-sharing behavior. Following Bock et al. (2005), some studies have investigated the antecedents of knowledge-sharing intention.

The antecedents of knowledge-sharing intention have been classified into contextual and personal factors. Regarding contextual factors, prior studies have reported that the 
following were positively related to knowledge-sharing intention: subjective norms (Al-Kurdi et al., 2020; Chow and Chan, 2008); support from supervisors and colleagues (Cabrera et al., 2006); social networks and shared goals (Chow and Chan, 2008); transformational leadership climate and team identity (Liu and Phillips, 2011); trust and psychological safety (Zhang et al., 2010); and, norms of reciprocity (Tamjidyamcholo et al., 2013). With regard to personal factors, it was found that satisfaction with the community and affective commitment (Hashim and Tan, 2015); openness to experience and self-efficacy (Cabrera et al., 2006); attitude toward knowledge sharing (Chow and Chan, 2008); and, knowledge system commitment (Hwang et al., 2018) promoted knowledge-sharing intention.

More importantly, KW is a part of sharing less knowledge, but they are not identical. That is, there are two types of situations where the sharing of less knowledge occurs. First, individuals would be unable to share their knowledge because they lack relevant knowledge (Kang, 2016). Second, individuals attempt to conceal or hide their knowledge that they could share (Tsay et al., 2014). The latter type is known as KW. One should be aware that KW may lead to sub-optimal performance of organizations through hindering the dissemination of best practices and innovation (Haas and Park, 2010; Tsay et al., 2014).

Lin and Huang (2010) found that KW was reduced by contextual factors such as trust and personal factors, including outcome expectation. Tsay et al. (2014) also reported that KW was promoted by knowledge-withholding self-efficacy and reduced by perceived organizational support, leader-member exchanges and team-member exchanges. More recently, Anaza and Nowlin (2017) found that the KW of a salesperson was encouraged by isolation from the company, internal competition, past opportunistic coworker behaviors, lack of knowledgesharing rewards, lack of feedback on knowledge sharing; and neuroticism.

As an antecedent of knowledge sharing and withholding, we focused on LG, that is, an active striving toward the development and growth of competence (Dweck, 1986; Grant and 
Dweck, 2003). The reason was that LG have been proven to promote intrinsic motivation to learn, self-regulation and the seeking of self-improvement information (Bouffard et al., 1995; Grant and Dweck, 2003; Janssen and Prins, 2007). Other studies also found that LG promoted knowledge sharing, presumably because individuals with higher LG would be interested in the development of their skills and would expect reciprocal feedback from others (Lu et al., 2012; Matzler and Muller, 2011). Kim and Lee (2013) also reported that LG promoted behaviors of collecting and donating knowledge. Based on the arguments and evidence above, we proposed the following hypotheses:

Hla. LG are positively related to knowledge-sharing intention toward other units.

H1b. LG are negatively related to KW from other units.

\section{Community of practice as a social learning system}

In the past three decades, CoPs have become a core concept of learning and knowledge management (Brown and Duguid, 1991; Ribeiro et al., 2010) and are believed to be the most important platforms for knowledge sharing within an organization (Botelho, 2018; du Plessis, 2008). Specifically, a CoP is a repository where knowledge is developed, maintained, and reproduced (Ardichvili et al., 2006; Brown and Duguid, 2001). Therefore, a CoP can be viewed as a social learning system (Fam, 2017; Wenger, 2010), in line with the SCT postulating that individuals partly determine the nature of their social environment and at the same time, they are influenced by it (Bandura, 1989).

It is important to note that most studies investigated the knowledge sharing process in the context of $\mathrm{CoP}$ but only a few studies measured $\mathrm{CoP}$ itself. The exception is Cadiz et al. (2009), who defined experienced $\mathrm{CoP}$ as the subjective experience of membership in a CoP and developed a measurement scale for experienced CoP, which consisted of open communication, 
a shared vocabulary, remembering previous lessons; and learning from one another. Following Cadiz et al. (2009), we adopted the concept of experienced CoP to examine the effect of a CoP on knowledge sharing in an organization.

According to Ardichvili (2008), there are three benefits to participating in a CoP: intellectual (e.g. developing one's expertise), emotional (e.g. increasing self-confidence); and material benefits (e.g. increasing one's salary). Of these three benefits, several studies indicated the importance of intellectual benefit. For example, using a survey of electronic CoPs, Wasko and Faraj (2000) reported that participants enjoyed learning and sharing knowledge with others in the CoP. Chen et al. (2018) studied software organizations and found that the main benefit of belonging to a $\mathrm{CoP}$ was the intrinsic motivation for learning. Importantly, Fahey et al. (2007) also argued that the extrinsic use of rewards had an unfavorable impact on members' intrinsic motivation to share knowledge in a virtual CoP, suggesting that members of CoPs are intrinsically motivated to exchange knowledge. Given the nature of a $\mathrm{CoP}$ as a social learning system (Fam, 2017; Wenger, 2010) and the empirical evidence, we proposed the following hypothesis.

H2. The experienced CoP within a unit is positively related to LG.

It is necessary to remember that members of a $\mathrm{CoP}$ often belong to a larger organization (Brown and Duguid, 2001) and that there may be potential tensions and conflicts among multiple communities (Handley et al., 2006). Notably, Ardichvili et al. (2003) reported that individuals often avoid contributing knowledge to the community due to fear of criticism or the risk of misleading the members. In addition, previous research indicated that individuals in CoPs tend to share knowledge more frequently with people with whom they have strong relationships or common expertise than with people with whom they do not (Christensen and Pedersen, 2018; Hwang et al., 2015). Tsai (2002) reported that a formal hierarchical structure 
inhibited knowledge sharing while social interaction promoted knowledge sharing within an organization. Furthermore, Harvey et al. (2013) stated that there were tensions between CoPs and professional bureaucracy. These studies suggested that individuals preferred to share knowledge within a known community but hesitate to engage in knowledge sharing across boundaries (Pan and Leidner, 2003). Therefore, a CoP within a unit is unlikely to have a direct impact on the unit's knowledge sharing or withholding intention toward other units.

Thus, we predicted that LG mediate the relationship between experienced CoP and knowledge sharing or withholding for two reasons. First, several studies reported the positive effect of LG on knowledge sharing (Kim and Lee, 2013; Lu et al., 2012; Matzler and Muller, 2011). Second, Jeon et al. (2011) found that in a CoP, intrinsic motivational factors had stronger effects on attitude toward knowledge sharing than extrinsic motivational factors did. Therefore, we proposed the following hypotheses:

$H 3 a$. LG fully and positively mediate the relationship between experienced CoP within a unit and knowledge-sharing intention toward other units.

$H 3 b$. LG fully and negatively mediate the relationship between experienced $\mathrm{CoP}$ within a unit and KW from other units.

Based on SCT (Bandura, 1989, 2001, 2005) and the hypotheses mentioned above, we developed the research model shown in Figure 1. This model focuses on the mediating role of LG in the relationship between the CoP within a unit to knowledge sharing with and withholding from other units. To verify the full mediation hypotheses, direct paths from experienced $\mathrm{CoP}$ to knowledge-sharing intention and $\mathrm{KW}$ were included in the model. 
Figure 1 Research model

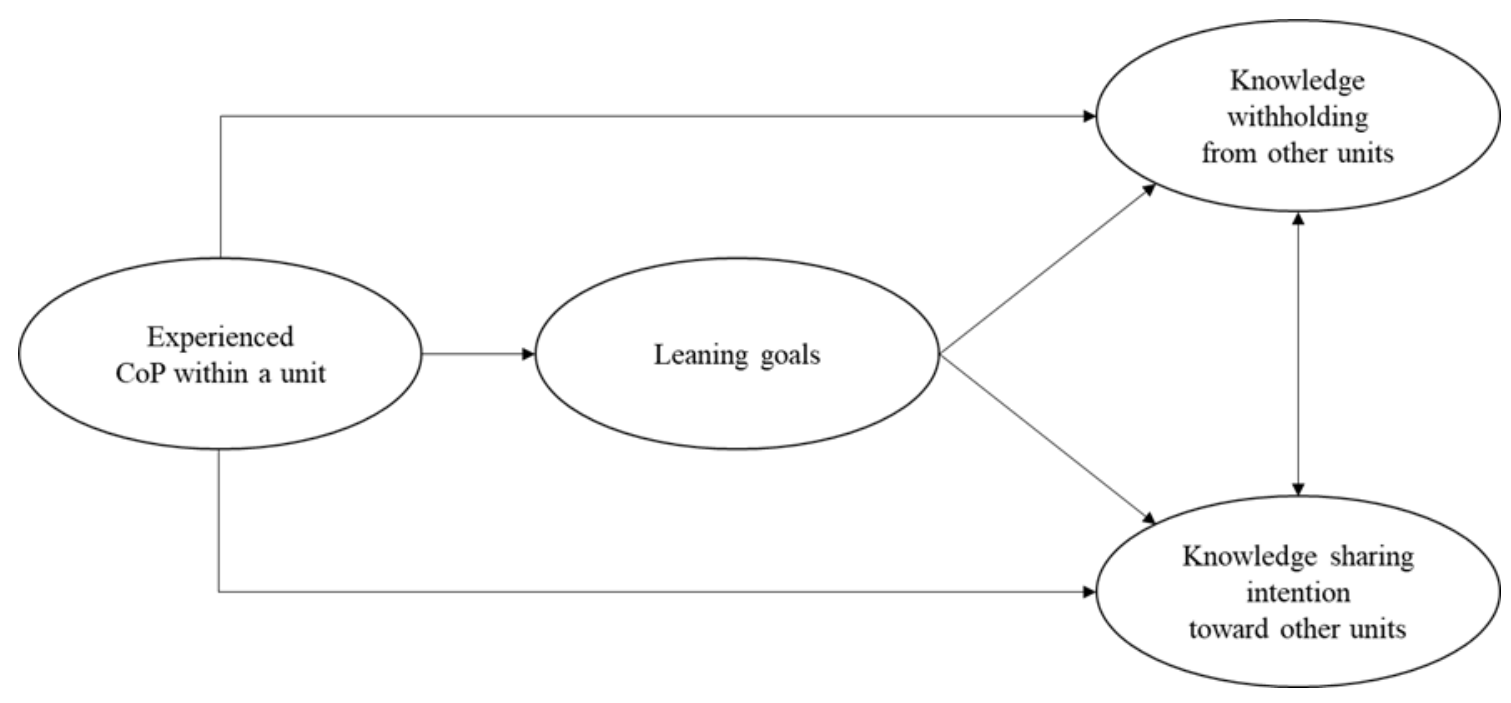

Table 1 Characteristics of respondents

\begin{tabular}{|c|c|c|}
\hline Demographic & Frequency & Perce \\
\hline \multicolumn{3}{|l|}{ Gender } \\
\hline Female & 226 & 85.9 \\
\hline Male & 37 & 14.1 \\
\hline \multicolumn{3}{|l|}{ Age } \\
\hline $20 \mathrm{~s}$ & 45 & 17.1 \\
\hline $30 \mathrm{~s}$ & 100 & 38.0 \\
\hline $40 \mathrm{~s}$ & 87 & 33.1 \\
\hline 50s or above & 31 & 11.8 \\
\hline
\end{tabular}

Tenure

9 years or below

10-19 years

20 years or above

Size of organization (Number of bed)

100-299

300-499

Type of organization

Acute 


\section{Methods}

\section{Data collection and procedures}

To test our model, we conducted a two-wave survey with nurses in hospitals. Hospitals were chosen as locations to conduct the survey because they have multi-disciplinary professional communities (Denis et al., 2001; Oborn and Dawson, 2010; Mørk et al., 2010). According to Nätti and Still (2007), professional service organizations are structured based on professional fields in which experts hold similar views and create social bonds with one another. In particular, CoPs often retard the spread of innovations in the health-care sector (Ferlie et al., 2005). Powell and Davies (2012) also reported that practices for improving medical services were hindered by inter-professional boundaries between the medical and nursing professions. Specifically, conflicts between doctors and nurses often emerge because of distinct professional identities (Liberati et al., 2016). Considering that the CoPs of professional nurses were examined in previous studies (e.g. Hara and Hew, 2007) and that nurses play important roles in improving interdisciplinary collaboration in health-care systems (Bender et al., 2013), our sample was appropriate for investigating the proposed research model.

A two-wave questionnaire survey with a one-month period between the waves was conducted at eight hospitals with nurses who had joined a large medical association. In the survey, CoP and LG were assessed at Time 1 whereas knowledge-sharing intention and KW were measured at Time 2 . The questionnaires were delivered through the administrative office of the medical association to 325 nurses and 263 valid questionnaires were obtained after removing missing values (response rate $=80.9 \%$ ). Table I shows the characteristics of the respondents, all of whom were staff-level nurses. The sample consisted of $85.9 \%$ women. The average tenure was 12.67 years (standard deviation $=9.15$ years). The distribution of respondents' age was as follows: $17.1 \%$ were younger than 29 years, 38.0 \% 30-39 years, $33.1 \% 40-49$ years and $11.8 \% 50$ years and older. Respondents worked for acute hospitals 
(55.9\%) and chronic hospitals (44.1), with 100-299 beds (36.5\%) and 300-499 beds $(63.5 \%)$.

\section{Measures}

As the questionnaire was in Japanese, we conducted a back-translation to check the equivalence between the original English version and the translated Japanese version, based on Cascio's (2012) guideline. All items were assessed on a five-point Likert scale ranging from 1 (strongly disagree) to 5 (strongly agree).

The CoP within the unit (Time 1) was assessed using a 12-item scale developed by Cadiz et al. (2009). As this scale consists of four dimensions, for the observable variables, we used the average item scores for the dimensions (parcels), following Coffman and MacCallum's (2005) parceling procedure. Because our sample was nurses, we replaced the term "my technical specialty" with "nursing department." Sample questionnaire items were: "I feel comfortable communicating freely with others in the nursing department" (open communication), "The nursing department has a unique vocabulary" (shared vocabulary), "Collaborating with other members of the nursing department helps me remember things that we have learned" (remembering previous lessons) and "Learning is shared among members of the nursing department" (learning from each other).

LG (Time 1) were evaluated using a five-item scale developed by Button et al. (1996). A sample item was: "I prefer to work on tasks that force me to learn new things."

Knowledge-sharing intention toward other units (Time 2) was measured using a fiveitem scale developed by Bock et al. (2005). Specifically, a two-item scale for "intention to share explicit knowledge" and a three-item scale for "intention to share implicit knowledge" were combined. A sample item was: "I intend to share my experience or know-how from work with other organizational members more frequently in the future." In the questions, we asked participants whether they shared their knowledge with other professionals such as doctors, 
technicians, and administrative staff.

KW from other units (Time 2) was assessed using a five-item scale developed by Lin and Huang (2010). A sample item was: "I avoid contributing knowledge as much as possible." In the questions, we asked participants whether they withheld their knowledge from other professionals, such as doctors, technicians, and administrative staff.

Gender $(1=$ male; $2=$ female $)$, age $(1=20 \mathrm{~s} ; 2=30 \mathrm{~s} ; 3=40 \mathrm{~s} ; 4=50$ s or more $)$, tenure (years of experience in the organization), size of organization ( $1=100-299$ beds; $2=300-499$ beds), and type of organization $(1=$ acute; 2 = chronic $)$ were included in the equation to control their effects.

\section{Analyses}

Structural equation modeling (SEM) using maximum likelihood estimation was adopted to test the model, because it can be applied to estimate mediating effects that involve multiple dependent variables simultaneously (Pek and Hoyle, 2016). In addition, a series of confirmatory factor analysis (CFA) were performed to assess the discriminant validity of the measurement of constructs. We conducted SEM and CFA by using Mplus Version 8.3 (Muthén and Muthén, 1998-2017), as the software provides the dual option of chi-square difference test in CFA, as well as Bootstrapping analysis for examining mediating effect in SEM. 
Table 2 Reliability and validity of constructs

\begin{tabular}{|c|c|c|c|c|}
\hline Construct & $\begin{array}{c}\text { Factor } \\
\text { loadings }\end{array}$ & $\begin{array}{l}\text { Cronbach's } \\
\text { alpha }\end{array}$ & CR & AVE \\
\hline Community of practice within a unit (COP) & & .82 & .83 & .56 \\
\hline COP1 & .66 & & & \\
\hline $\mathrm{COP} 2$ & .62 & & & \\
\hline $\mathrm{COP} 3$ & .86 & & & \\
\hline $\mathrm{COP} 4$ & .82 & & & \\
\hline Learning goals (LG) & & .83 & .83 & .50 \\
\hline LG1 & .69 & & & \\
\hline LG2 & .67 & & & \\
\hline LG3 & .70 & & & \\
\hline LG4 & .77 & & & \\
\hline LG5 & .70 & & & \\
\hline Knowledge-sharing intension toward other units (KSI) & & .90 & .91 & .66 \\
\hline KSI1 & .72 & & & \\
\hline KSI2 & .83 & & & \\
\hline KSI3 & .87 & & & \\
\hline KSI4 & .82 & & & \\
\hline KSI5 & .81 & & & \\
\hline Knowledge withholding from other units (KW) & & .82 & .87 & .58 \\
\hline KW1 & .76 & & & \\
\hline KW2 & .75 & & & \\
\hline KW3 & .76 & & & \\
\hline KW4 & .75 & & & \\
\hline KW5 & .79 & & & \\
\hline
\end{tabular}

Notes: $\mathrm{CR}=$ Composite reliability; $\mathrm{AVE}=$ Average variance extracted. $\mathrm{COP} 1, \mathrm{COP} 2, \mathrm{COP} 3$, and COP4 are the average item scores for the dimensions (parcels).

\section{Results}

\section{Measurement validation}

Internal consistency and convergent validity were assessed using Cronbach's alpha, composite reliability (CR) and average variance extracted (AVE). As shown in Table 2, the Cronbach's alpha and CR values of all the constructs exceeded the cutoff level of 0.07 , respectively (Nunnally, 1978), indicating the internal consistency of the constructs. The AVE estimates range from 0.50 to 0.66 , indicating the convergent validity of the constructs, based on the 0.50 criterion (Bagozzi and Yi, 1988).

The discriminant validity of the hypothesized model was examined using a CFA. Table 
3 shows the results of a series of CFAs, showing that the hypothesized four-factor model exhibited a better fit to the data than the three -, two -, and one-factor models. In addition, the four-factor model showed an acceptable fit to the data $\left(\chi^{2}=224.92\right.$; degree of freedom $(\mathrm{df})=$ $146 ; \chi^{2} / \mathrm{df}=1.54$; comparative fit index $(\mathrm{CFI})=0.938$; standardized root mean square residual $(\mathrm{SRMR})=0.051$; root mean square error of approximation $($ RMSEA $)=0.045)$, based on existing criteria (Hu and Bentler, 1999; Lane et al., 2006). Table 4 also shows that the AVE estimates for the four constructs were greater than the shared variance estimate. These results satisfy the discriminant validity requirements of the hypothesized model.

Table 3 Comparison of CFAs

\begin{tabular}{lcccccc}
\hline \multicolumn{1}{c}{ Models } & $\chi^{2}$ & $d f$ & $\Delta \chi^{2}$ & CFI & SRMR & RMSEA \\
\hline 4-Factor model & 224.92 & 146 & & .938 & .051 & .045 \\
3-Factor model (KSI + KW) & 472.72 & 149 & $247.79 * * *$ & .744 & .112 & .091 \\
2-Factor model (KSI + KW+ LG) & 621.75 & 151 & $149.03 * * *$ & .628 & .136 & .109 \\
1-Factor mode & 798.38 & 152 & $176.63 * * *$ & .489 & .156 & .127 \\
\hline
\end{tabular}

Notes. $* * * p<.001 .4$-factor model: each variable was loaded on a single factor; In the 3-factor model, knowledge sharing intention toward other units (KSI) and knowledge withholding from other units (KW) were combined; In the 2factor model, KSI, KW, and learning goals (LG) were combined; In the 1-factor model: all variables were combined in a single factor.

Table 4 Descriptive statistics and correlations

\begin{tabular}{|c|c|c|c|c|c|c|c|c|c|c|c|}
\hline Variable & $M$ & $S D$ & 1 & 2 & 3 & 4 & 5 & 6 & 7 & 8 & \\
\hline 1. Gender & 1.14 & 0.35 & - & & & & & & & & \\
\hline 2. Age & 2.40 & 0.91 & -.07 & - & & & & & & & \\
\hline 3. Tenure & 12.67 & 9.15 & -.10 & $.31 * * *$ & - & & & & & & \\
\hline 4. Size of organization & 1.63 & 0.48 & .10 & $-.20 * *$ & .07 & - & & & & & \\
\hline 5. Type of organization & 1.44 & 0.50 & -.07 & $.16 * *$ & -.02 & $-.27 * * *$ & - & & & & \\
\hline 6. CoP within a unit (T1) & 3.68 & 0.50 & -.08 & -.07 & -.06 & -.04 & -.02 & - & .18 & .06 & .01 \\
\hline 7. Learning goals (T1) & 3.77 & 0.54 & -.05 & $.16 *$ & .02 & -.04 & .06 & $.42_{* * *}^{* *}$ & - & .22 & .07 \\
\hline 8. KSI toward other units (T2) & 3.16 & 0.77 & .11 & $.18 * *$ & .06 & -.11 & .11 & $.24 * * *$ & $.47 * * *$ & - & .12 \\
\hline 9. KW from other units (T2) & 2.67 & 0.62 & .01 & $-.19 * *$ & -.07 & -.01 & -.01 & .01 & $-.26_{* * *}^{*}$ & $-.34 * * *$ & - \\
\hline
\end{tabular}


To examine whether a common method variance (CMV) issue exists, we conducted Harman's single factor test by performing an exploratory factor analysis (based on a principal factor with no rotation) with all the items. If a single factor emerges or a general factor accounts for the majority of the covariance, the effects of common method bias may be serious (Podsakoff et al., 2003). The results of the test were as follows: six factors were extracted and the first factor accounted for $24.3 \%$ of the total variance. The results in Table 3 also indicate that the four-factor model showed a significantly better fit to the data than the three-factor model $\left(\Delta \chi^{2}=247.79, p<0.001\right)$. These results suggested that common method bias did not seriously affect the results. As procedural remedies proposed by Podsakoff et al. (2003), we introduced a time lag between the measurement of constructs, to minimize CMV.

\section{Hypothesis testing}

We performed SEM to examine the proposed research model. Hla predicted that LG are positively related to knowledge-sharing intention toward other units, whereas $H 1 b$ predicted that LG are negatively related to KW from other units. Table 5 and Figure 2 show that learning goals were positively related to knowledge-sharing intention toward other units $(0.50, p<$ $0.001)$, and that LG were negatively related to $\mathrm{KW}$ from other units $(-0.38, p<0.001)$, supporting $H 1 a$ and $H 1 b$. The results suggest that employees with a high learning goal have a greater intention to share their knowledge with other units; and have a lesser intention to hide their knowledge. $\mathrm{H} 2$ predicted that the experienced $\mathrm{CoP}$ within a unit is positively related to LG. Table 5 and Figure 2 also show that experienced CoP within a unit was positively related to $\operatorname{LG}(0.53, p<0.001)$, which supported $H 2$. The results indicate that employees who belong to $\mathrm{CoP}$ within a unit have higher LG. 
Table 5 Results of structural equation modeling

\begin{tabular}{|c|c|c|c|c|}
\hline \multicolumn{3}{|c|}{ Structural path } & \multirow{2}{*}{$\begin{array}{c}\begin{array}{c}\text { Standardized } \\
\text { estimate }\end{array} \\
.53\end{array}$} & \multirow{2}{*}{$\frac{t \text {-value }}{8.62^{* * *}}$} \\
\hline $\mathrm{CoP}$ within a unit & $\Rightarrow$ & Learning goals & & \\
\hline CoP within a unit & $\Rightarrow$ & KSI toward other units & .06 & 0.64 \\
\hline Learning goals & $\Rightarrow$ & KSI toward other units & .50 & $6.22^{* * *}$ \\
\hline CoP within a unit & $\Rightarrow$ & $\mathrm{KW}$ from other units & .17 & 1.88 \\
\hline Learning goals & $\Rightarrow$ & $\mathrm{KW}$ from other units & -.38 & $-4.09^{* * *}$ \\
\hline \multicolumn{5}{|l|}{ Control variables } \\
\hline Gender & $\Rightarrow$ & Learning goals & .01 & 0.09 \\
\hline Age & $\Rightarrow$ & Learning goals & .20 & $3.37^{* *}$ \\
\hline Tenure & $\Rightarrow$ & Learning goals & -.01 & -0.16 \\
\hline Type & $\Rightarrow$ & Learning goals & .05 & 0.68 \\
\hline Size & $\Rightarrow$ & Learning goals & .04 & 0.61 \\
\hline Gender & $\Rightarrow$ & KSI toward other units & .17 & $2.83^{* *}$ \\
\hline Age & $\Rightarrow$ & KSI toward other units & .08 & 1.24 \\
\hline Tenure & $\Rightarrow$ & KSI toward other units & .05 & 0.99 \\
\hline Type & $\Rightarrow$ & KSI toward other units & .06 & 0.99 \\
\hline Size & $\Rightarrow$ & KSI toward other units & -.08 & -1.29 \\
\hline Gender & $\Rightarrow$ & $\mathrm{KW}$ from other units & -.01 & -0.23 \\
\hline Age & $\Rightarrow$ & $\mathrm{KW}$ from other units & -.13 & -1.77 \\
\hline Tenure & $\Rightarrow$ & $\mathrm{KW}$ from other units & -.02 & -0.26 \\
\hline Type & $\Rightarrow$ & $\mathrm{KW}$ from other units & .03 & 0.44 \\
\hline Size & $\Rightarrow$ & $\mathrm{KW}$ from other units & -.01 & -0.09 \\
\hline KSI toward other units & $\Leftrightarrow$ & $\mathrm{KW}$ from other units & -.28 & $-3.25^{* *}$ \\
\hline
\end{tabular}


Table 6 Results of indirect effects based on Bootstrap estimates

\begin{tabular}{cccrrrr}
\hline \multirow{2}{*}{ Indirect effects } & \multirow{2}{*}{ Estimate } & \multirow{2}{*}{$\mathrm{SE}$} & \multicolumn{3}{c}{ Bias-corrected 95\% CI } & \multirow{2}{*}{ Hypothesis } \\
\cline { 5 - 6 } $\mathrm{CoPs} \rightarrow \mathrm{LG} \rightarrow \mathrm{KSI}$ & .26 & $.05^{* * *}$ & .19 & .35 & H3a \\
$\mathrm{CoPs} \rightarrow \mathrm{LG} \rightarrow \mathrm{KW}$ & -.20 & $.06^{* * *}$ & -.30 & -.12 & H3b \\
\hline
\end{tabular}

Notes $. \mathrm{LG}=$ learning goals. $\mathrm{KSI}=$ knowledge sharing intention. $\mathrm{KW}=$ knowledge withholding. Standardized estimates are reported. $* * * p<.001$. Bootstrap sample size $=2000$.

Figure 2 Summary of results

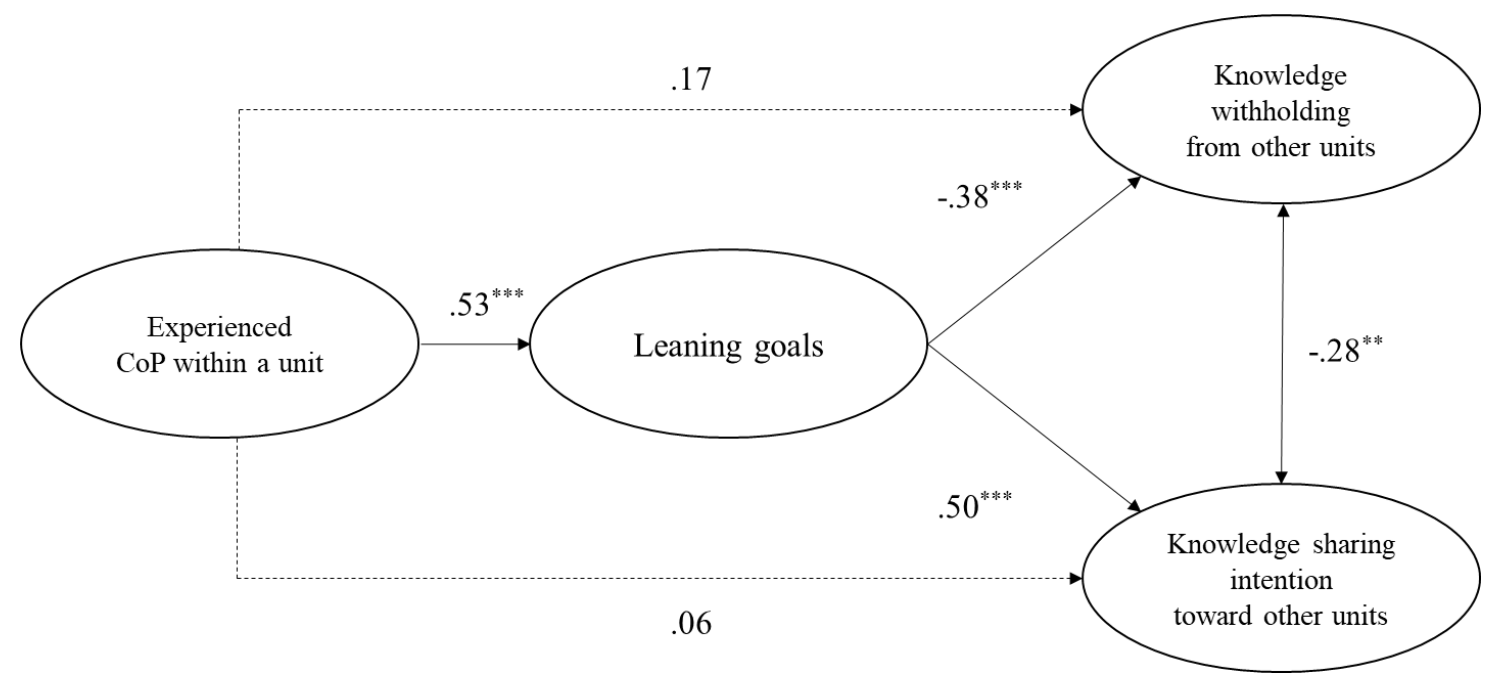

Notes. ${ }^{* *} p<.01,{ }^{* * *} p<.001$.

We hypothesized that LG would fully and positively mediate the relationship between experienced CoP within a unit and knowledge-sharing intention toward other units $(\mathrm{H} 3 \mathrm{a} a)$, and that LG would fully and negatively mediate the relationship between experienced CoP within a unit and $\mathrm{KW}$ from other units $(H 3 b)$. To test the mediation hypotheses, we conducted bootstrapping analyses with 2,000 samples. As shown in Table 6, the results indicate that the positive indirect effect of experienced $\mathrm{CoP}$ within the unit on knowledge-sharing intention toward other units through LG was significant (indirect effect $=0.26, p<0.001$ ) and the $95 \%$ confidence interval (CI) for the indirect effect did not include zero $(95 \%$ CI $[0.19,0.35])$. Furthermore, the negative indirect effect of experienced $\mathrm{CoP}$ on $\mathrm{KW}$ from other units through LG was significant (indirect effect $=-0.20, p<0.001$ ) and the $95 \% \mathrm{CI}$ for the indirect effect did not include zero $(95 \% \mathrm{CI}[-0.30,-0.12])$. Considering that the direct effects of CoP within the 
unit on knowledge-sharing intention toward other units and $\mathrm{KW}$ from other units were not significant $(0.06$, ns; and 0.17 , ns, respectively), $H 3 a$ and $H 3 b$ were supported. These results suggest that LG play an important role in linking experienced CoP to knowledge-sharing intention and $\mathrm{KW}$.

\section{Discussion}

Although prior studies suggested that potential tensions and conflicts exist among multiple communities (Christensen and Pedersen, 2018; Handley et al., 2006; Hwang et al., 2015; Tsai, 2002), few quantitative studies examined the process of knowledge sharing across CoPs. Based on SCT (Bandura, 1989, 2001, 2005), this study found that LG play a critical role in linking the CoP within a unit to the unit's knowledge sharing and KW with other units.

\section{Theoretical implications}

This study contributes to the literature on knowledge management by extending the understanding of the knowledge-sharing process in the following three ways: First, we found that LG fully mediated the effect of $\mathrm{CoP}$ on knowledge-sharing intention and on $\mathrm{KW}$ over boundaries. The results indicate that $\mathrm{CoP}$ can promote knowledge sharing across professional boundaries only through stimulating employees' desire to learn. As Jeon et al. (2011) state, intrinsic or intellectual motivation rather than extrinsic one, may be a primary driver of knowledge sharing "across" communities especially in pluralistic organizations such as hospitals. Although it was not significant, the results show that CoP enhanced KW $(0.17, p<$ 0.06), suggesting that nurses tend to resist sharing their knowledge with employees of other units. The findings indicate that LG may reduce such resistance by enhancing employees' intrinsic motivation for learning and development (Bouffard et al., 1995; Grant and Dweck, 2003; Janssen and Prins, 2007; Lu et al., 2012; Matzler and Muller, 2011). This study contributes to the existing literature on $\mathrm{CoP}$ and knowledge sharing by identifying the role of 
LG in disseminating knowledge across professional boundaries or fields, which has been a challenging issue in prior research on CoPs (Christensen and Pedersen, 2018; Handley et al., 2006; Harvey et al., 2013; Hwang et al., 2015; Tsai, 2002).

Second, individuals' LG were found to be able to promote knowledge-sharing intention in a CoP and to discourage the CoP's KW. The results can be explained as follows: members with high LG may share their knowledge because they would like to upgrade their skills and knowledge by collecting knowledge from individuals outside their professional CoP (Lu et al., 2012). Although the findings were consistent with those of previous studies reporting a positive relationship between LG and knowledge sharing within a community (Kim and Lee, 2013; Lu et al., 2012; Matzler and Muller, 2011), this study may be the first to identify the role of LG activated by $\mathrm{CoP}$ in reducing $\mathrm{KW}$, which is not identical to sharing less knowledge. The results can be interpreted that LG prevent employees from hiding the knowledge that they could share (Tsay et al., 2014). The findings suggest that cultivating LG through CoP is a key practice for crossing "invisible walls" as inter-professional boundaries (Liberati et al., 2016; Powell and Davies, 2012; Tasselli, 2015) and dealing with tensions and conflicts among them (Christensen and Pedersen, 2018; Handley et al., 2006; Hwang et al., 2015).

Third, the results indicated that experienced CoP within a unit enhanced members' LG. These findings suggest that $\mathrm{CoP}$ works as a social learning system (Wenger, 2010) that encourages members to be engaged in the process of developing, maintaining, and reproducing knowledge (Ardichvili et al., 2006; Brown and Duguid, 2001; Fam, 2017), which may stimulate their intellectual interests (Ardichvili, 2008). Specifically, CoP which includes open communication, shared vocabulary, remembering previous lessons; and learning from one another (Cadiz et al., 2009), may promote employees' active striving toward development and growth of competence (Dweck, 1986; Grant and Dweck, 2003). Although previous studies have qualitatively investigated the role of CoPs as learning sites (Pyrko et al., 2019; Ribeiro et al., 
2010), this study is the first to quantitatively examine the process by which CoPs enhance their members' learning and development in terms of goal orientation.

\section{Practical implications}

This study has three practical implications for knowledge management practitioners. First, an organization can facilitate knowledge sharing across organizational units by helping members enhance their LG, especially in health-care organizations, which comprise multiple professional communities (Denis et al., 2001; Mørk et al., 2010; Oborn and Dawson, 2010). One effective way to promote knowledge sharing across boundaries may be to provide employees with learning goal orientation training (Noordzij et al., 2013). Such training may help professionals understand the concept of "learning-goal orientation" as well as methods of setting LG. Hiring employees with high LG is also essential for promoting knowledge management.

Second, to prevent employees' KW, organizations should help professional leaders of CoPs such as nursing managers organize their communities so that members' pursuit of LG is activated. It is important for knowledge managers to note that intellectual benefits from experienced CoP can play a key role in reducing the perceived risks associated with members' knowledge sharing, as well as in creating effective knowledge sharing with other units. Periodically assessing employees' learning satisfaction through community activities may be an effective way to monitor and improve the intellectual benefits of CoPs, especially for healthcare organizations, where knowledge sharing among interdisciplinary units is imperative.

Finally, knowledge managers need to distinguish $\mathrm{KW}$ from the sharing of less knowledge. The correlation between these two variables was -0.34 , showing that $\mathrm{KW}$ is a factor that inhibits knowledge sharing but is not an antonym to "knowledge sharing." As mentioned, $\mathrm{KW}$ is an intentional attempt to conceal knowledge that individuals could share (Tsay et al., 2014). When community members tend to withhold their knowledge, the resulting closed CoP 
has less impact on the knowledge of the entire organization. Thus, knowledge managers and community leaders must monitor the degree of $\mathrm{KW}$ within CoPs and prevent it by enhancing members' intrinsic motivation to learn.

\section{Limitations and future research}

Finally, we acknowledge certain limitations of the present study. First, the sample was limited to nurses from Japanese hospitals. Although hospitals are appropriate research sites for examining multiple communities (Oborn and Dawson, 2010; Mørk et al., 2010), indigenous or professional culture may have affected the results. Future research should reexamine our model by using data from other cultures or occupations.

Second, we conducted a two-wave survey to investigate the model but experienced $\mathrm{CoP}$ and LG were only measured at Time 1 . To verify a causal relationship, it is desirable to conduct a three-wave survey in the future.

Finally, this study examined the mediating role of LG, which are closely related to the intellectual benefits of a CoP, but there are also emotional (e.g. increased self-confidence) and material (e.g. improved salary) benefits to participating in a CoP (Ardichvili, 2008). Therefore, these factors also need to be investigated as mediators of the relationship between CoP and knowledge sharing.

\section{Conclusion}

As there are potential tensions and conflicts among the multiple communities in the organization, it is a challenge for knowledge managers to facilitate knowledge sharing across boundaries. We found that employees' LG play a key role in removing barriers to knowledge sharing among units. The findings suggest that enhancing the intellectual benefits from CoPs is significant for promoting knowledge sharing across all units and reducing $\mathrm{KW}$ within the entire 
organization. This study contributes to the literature by identifying the psychological mechanism by which CoPs influence knowledge sharing and withholding across boundaries. To foster more effective knowledge management, managers must enhance CoP members' intrinsic motivation to learn, which will promote knowledge sharing and reduce KW.

\section{References}

Agency for Healthcare Research and Quality (2021), "Innovations exchange learning communities", available at: https://innovations.ahrq.gov/learning-communities (accessed 25 February 2021).

AHRQ Health Care Innovations Exchange (2016), "Developing and implementing learning communities: findings and lessons from the AHRQ Health Care Innovations Exchange", available at: https://innovations.ahrq.gov (accessed 25 February 2021).

Al-Kurdi, O. F., El-Haddadeh, R. and Eldabi, T. (2020), "The role of organisational climate in managing knowledge sharing among academics in higher education", International Journal of Information Management, Vol. 50, pp. 217-227.

Anaza, N. A. and Nowlin, E. L. (2017), “What's mine is mine: a study of salesperson knowledge withholding \& hoarding behavior", Industrial Marketing Management, Vol. 64, pp. 14-24.

Ardichvili, A. (2008), "Learning and knowledge sharing in virtual communities of practice: motivators, barriers, and enablers”, Advances in Developing Human Resources, Vol. 10 No. 4, pp. 541-554.

Ardichvili, A., Maurer, M., Li, W., Wentling, T. and Stuedemann, R. (2006), "Cultural influences on knowledge sharing through online communities of practice", Journal of Knowledge Management, Vol. 10 No. 1, pp. 94-107.

Ardichvili, A., Page, V. and Wentling, T. (2003), "Motivation and barriers to participation in virtual knowledge-sharing communities of practice", Journal of Knowledge Management, 
Vol. 7 No. 1, pp. 64-77.

Argote, L. and Miron-Spektor, E. (2011), "Organizational learning: from experience to knowledge", Organization Science, Vol. 22 No. 5, pp. 1123-1137.

Bagozzi, R. P. and Yi, Y. (1988), “On the evaluation of structural equation models”, Journal of the Academy of Marketing Science, Vol.16 No. 1, pp. 74-94.

Bandura, A. (1989), "Human agency in social cognitive theory", American Psychologist, Vol. 44 No. 9, pp. 1175-1184.

Bandura, A. (2001), "Social cognitive theory: an agentic perspective", Annual Review of Psychology, Vol. 52 No. 1, pp. 1-26.

Bandura, A. (2005), "The evolution of social cognitive theory", in Smith, K. G. and Hitt, M. A. (Eds), Great Minds in Management, Oxford University Press, Oxford, pp. 9-35.

Barbosu, C. M., Perez-Ramos, J. G., Demment, M., Fogg, T., Chang, J., Aladin, B., Smith, C., De Ver Dye, T. and Doll, T. (2017). "Use of an online provider learning community to assess clinical HIV/HCV/STDs-related training needs", Journal of Clinical and Translational Science, Vol. 1, pp. 51-51.

Bender, M., Connelly, C. and Brown, C. (2013), "Interdisciplinary collaboration: the role of the clinical nurse leader”, Journal of Nursing Management, Vol. 21 No. 1, pp. 165-174.

Bock,G., Zmud, R. W. and Lee, J. (2005), "Behavioral intention formation in knowledge sharing: examining the roles of extrinsic motivators, social-psychological factors, and organizational climate", MIS Quarterly, Vol. 29 No. 1, pp. 87-111.

Botelho, T. L. (2018), “Here's an opportunity: knowledge sharing among competitors as a response to buy-in uncertainty", Organization Science, Vol. 29 No. 6, pp. 1033-1055.

Bouffard, T., Boisvert, J., Vezeau, C. and Larouche, C. (1995), “The impact of goal orientation on self-regulation and performance among college students", British Journal of Educational Psychology, Vol. 65 No. 3, pp. 317-329. 
Brown, J. S. and Duguid, P. (1991), “Organizational learning and communities-of-practice: toward a unified view of working, learning, and innovation", Organization Science, Vol. 2 No. 1, pp. 40-57.

Brown, J. S. and Duguid, P. (2001), "Knowledge and organization: a social-practice perspective", Organization Science, Vol. 12 No. 2, pp. 198-213.

Button, S. B., Mathieu, J. E. and Zajac, D. M. (1996), "Goal orientation in organizational research: a conceptual and empirical foundation", Organizational Behavior and Human Decision Processes, Vol. 67 No. 1, pp. 26-48.

Cabrera, E. F. and Cabrera, A. (2005), "Fostering knowledge sharing through people management practices", The International Journal of Human Resource Management, Vol. 16 No. 5 , pp. $720-735$.

Cabrera, A., Collins, W. C. and Salgado, J. F. (2006), "Determinants of individual engagement in knowledge sharing”, The International Journal of Human Resource Management, Vol. 17 No. 2, pp. 245-264.

Cadiz, D., Sawyer, J. E. and Griffith, T. L. (2009), "Developing and validating field measurement scales for absorptive capacity and experienced community of practice", Educational and Psychological Measurement, Vol. 69 No. 6, pp. 1035-1058.

Carpenter, D., Hassell, S., Mardon, R., Fair, S., Johnson, M., Siegel, S., and Nix, M. (2018), "Using learning communities to support adoption of health care innovations", The Joint Commission Journal on Quality and Patient Safety, Vol. 44 No. 10, pp. 566-573.

Cascio, W. F. (2012), "Methodological issues in international HR management research", The International Journal of Human Resource Management, Vol. 23 No. 12, pp. 2532-2545.

Chen, H., Nunes, M. B., Ragsdell, G. and An, X. (2018), "Extrinsic and intrinsic motivation for experience grounded tacit knowledge sharing in Chinese software organisations", Journal of Knowledge Management, Vol. 22 No. 2, pp. 478-498. 
Christensen, P. H. and Pedersen, T. (2018), "The dual influences of proximity on knowledge sharing”, Journal of Knowledge Management, Vol. 22 No. 8, pp. 1782-1802.

Chow, W. S. and Chan, L. S. (2008), "Social network, social trust and shared goals in organizational knowledge sharing", Information \& Management, Vol. 45 No. 7, pp. 458465.

Coffman, D. L. and MacCallum, R. C. (2005), "Using parcels to convert path analysis models into latent variable models", Multivariate Behavioral Research, Vol. 40 No. 2, pp. 235259.

Denis, J. L., Lamothe, L. and Langley, A. (2001), “The dynamics of collective leadership and strategic change in pluralistic organizations", Academy of Management Journal, Vol. 44 No. 4, pp. 809-837.

Du Plessis, M. (2008), “The strategic drivers and objectives of communities of practice as vehicles for knowledge management in small and medium enterprises", International Journal of Information Management, Vol. 28 No. 1, pp. 61-67.

Dweck, C. (1986), "Motivational process affecting learning”, American Psychologist, Vol. 41 No. 10, pp. 1040-1048.

Fahey, R., Vasconcelos, A. C. and Ellis, D. (2007), “The impact of rewards within communities of practice: a study of the SAP online global community", Knowledge Management Research \& Practice, Vol. 5 No. 3, pp. 186-198.

Fam, D. (2017), "Facilitating communities of practice as social learning systems: a case study of trialling sustainable sanitation at the University of Technology Sydney (UTS)", Knowledge Management Research \& Practice, Vol. 15 No. 3, pp. 391-399.

Ferlie, E., Fitzgerald, L., Wood, M. and Hawkins, C. (2005), "The nonspread of innovations: the mediating role of professionals", Academy of Management Journal, Vol. 48 No. 1, pp. 117-134. 
Fishbein, M. and Ajzen, I. (1975), Beliefs, Attitude, Intention and Behavior: An Introduction to Theory and Research, Addison-Wesley Publishing Company, Reading, MA.

Furlong, G. P. and Johnson, L. (2003), "Community of practice and metacapabilities", Knowledge Management Research \& Practice, Vo. 1 No. 2, pp. 102-112.

Grant, H. and Dweck, C.S. (2003), “Clarifying achievement goals and their impact”, Journal of Personality and Social Psychology, Vol. 85 No. 3, pp. 541-553.

Haas, A. Abonneau, D., Borzillo, S. and Guillaume, L. (2020), “Afraid of engagement? Towards an understanding of engagement in virtual communities of practice", Knowledge Management Research \& Practice, doi:10.1080/14778238.2020.1745704.

Haas, M. R. and Park, S. (2010), "To share or not to share? Professional norms, reference groups, and information withholding among life scientists", Organization Science, Vol. 21 No. 4, pp. 873-891.

Handley, K., Sturdy, A., Fincham, R. and Clark, T. (2006), "Within and beyond communities of practice: making sense of learning through participation, identity and practice", Journal of Management Studies, Vol. 43 No. 3, pp. 641-653.

Hansen, M. T., Mors, M. L. and Løvås, B. (2005), "Knowledge sharing in organizations: multiple networks, multiple phases", Academy of Management Journal, Vol. 48 No. 5, pp. 776-793.

Hara, N. and Hew, K. F. (2007), "Knowledge-sharing in an online community of health-care professionals", Information Technology \& People, Vol. 20 No. 3, pp. 235-261.

Harvey, J., Cohendet, P., Simon, L. and Dubois, L. (2013), "Another cog in the machine: designing communities of practice in professional bureaucracies", European Management Journal, Vol. 31 No. 1, pp. 27-40.

Hashim, K. F. and Tan, F. B. (2015), “The mediating role of trust and commitment on members' continuous knowledge sharing intention: a commitment-trust theory perspective", 
International Journal of Information Management, Vol. 35 No. 2, pp. 145-151.

Hu, L. and Bentler, P. M. (1999), “Cutoff criteria for fit indexes in covariance structure analysis: conventional criteria versus new alternatives", Structural Equation Modeling: A Multidisciplinary Journal, Vol. 6 No.1, pp. 1-55.

Hwang, Y., Lin, H. and Shin, D. (2018), “Knowledge system commitment and knowledge sharing intention: the role of personal information management motivation", International Journal of Information Management, Vol. 39, pp. 220-227.

Hwang, E. H., Singh, P. V. and Argote, L. (2015), “Knowledge sharing in online communities: learning to cross geographic and hierarchical boundaries", Organization Science, Vol. 26 No. 6, pp. 1593-1611.

Ipe, M. (2003), "Knowledge sharing in organizations: a conceptual framework", Human Resource Development Review, Vol. 2 No. 4, pp. 337-359.

Janssen, O. and Prins, J. (2007), “Goal orientations and the seeking of different types of feedback information", Journal of Occupational and Organizational Psychology, Vol. 80 No. 2, pp. 235-249.

Jeon, S., Kim, Y. and Koh, J. (2011), “An integrative model for knowledge sharing in communities-of-practice”, Journal of Knowledge Management, Vol. 15 No. 2, pp. 251-269.

Kang, S. (2016), "Knowledge withholding: psychological hindrance to the innovation diffusion within an organization”, Knowledge Management Research \& Practice, Vol. 14 No. 1, pp. 144-149.

Kim, S. S. (2019), "The effect of social contexts and formation of individualism-collectivism orientation on knowledge sharing intention: the case of workers in Korea", Journal of Knowledge Management, Vol. 24 No. 2, pp. 196-215.

Kim, T. T. and Lee, G. (2013), "Hospitality employee knowledge-sharing behaviors in the relationship between goal orientations and service innovative behavior", International 
Journal of Hospitality Management, Vol. 34, pp. 324-337.

Lane, C. E., Butts, M. M. and Michels, L. M. (2006), “The sources of four commonly reported cutoff criteria: what did they really say?", Organizational Research Methods, Vol. 9 No. 2, pp. $202-220$.

Liberati, E. G., Gorli, M. and Scaratti, G. (2016), “Invisible walls within multidisciplinary teams: disciplinary boundaries and their effects on integrated care", Social Science \& Medicine, Vol. 150, pp. 31-39.

Lin, T. and Huang, C. (2010), "Withholding effort in knowledge contribution: the role of social exchange and social cognitive on project teams", Information \& Management, Vol. 47 No. 3, pp. 188-196.

Liu, Y. and Phillips, J. S. (2011), "Examining the antecedents of knowledge sharing in facilitating team innovativeness from a multilevel perspective", International Journal of Information Management, Vol. 31 No. 1, pp. 44-52.

Lu, L., Lin, X. and Leung, K. (2012), “Goal orientation and innovative performance: the mediating roles of knowledge sharing and perceived autonomy", Journal of Applied Social Psychology, Vol. 42, pp. E180-E197.

Matzler, K. and Mueller, J. (2011), “Antecedents of knowledge sharing: examining the influence of learning and performance orientation", Journal of Economic Psychology, Vol. 32 No. 3, pp. 317-329.

Mørk, B. E., Hoholm, T., Ellingsen, G., Edwin, B. and Aanestad, M. (2010), “Challenging expertise: on power relations within and across communities of practice in medical innovation”, Management Learning, Vol. 41 No. 5, pp. 575-592.

Muthén, L. K. and Muthén, B. O. (1998-2017), Mplus User's Guide. Muthén \& Muthén, Los Angeles, CA.

Myers, R. E., DiCarlo, M., Romney, M., Fleisher, L., Sifri, R., Soleiman, J., Lambert, E. and 
Rosenthal, M. (2018), "Using a health system learning community strategy to address cancer disparities", Learning Health Systems, Vol. 2 No. 4, p. e10067.

Nätti, S. and Still, J. (2007), "The influence of internal communities of practice on customer perceived value in professional service relationships", The Service Industries Journal, Vol. 27 No. 7, pp. 893-905.

Noordzij, G., van Hooft, E. J., van Mierlo, H., van Dam, A. and Born, M. P. (2013), “The effects of a learning-goal orientation training on self-regulation: a field experiment among unemployed job seekers”, Personnel Psychology, Vol. 66 No. 3, pp. 723-755.

Nunnally, J. C. (1978), Psychometric Theory, 2nd ed., McGraw-Hill, New York, NY.

Oborn, E. and Dawson, S. (2010), "Learning across communities of practice: an examination of multidisciplinary work", British Journal of Management, Vol. 21 No. 4, pp. 843-858.

Pan, S. L. and Leidner, D. E. (2003), "Bridging communities of practice with information technology in pursuit of global knowledge sharing", The Journal of Strategic Information Systems, Vol. 12 No. 1, pp. 71-88.

Pek, J. and Hoyle, R. H. (2016), "On the (in)validity of tests of simple mediation: threats and solutions", Social and Personality Psychology Compass, Vol. 10 No. 3, pp. 150-163.

Podsakoff, P. M., MacKenzie, S. B., Lee, J. and Podsakoff, N. P. (2003), “Common method biases in behavioral research: a critical review of the literature and recommended remedies", Journal of Applied Psychology, Vol. 88 No. 5, pp. 879-903.

Powell, A. E. and Davies, H. T. (2012), "The struggle to improve patient care in the face of professional boundaries”, Social Science \& Medicine, Vol. 75 No. 5, pp. 807-814.

Pyrko, I., Dörfler, V. and Eden, C. (2019), “Communities of practice in landscapes of practice”, Management Learning, Vol. 50 No. 4, pp. 482-499.

Ribeiro, R., Kimble, C. and Cairns, P. (2010), "Quantum phenomena in communities of practice”, International Journal of Information Management, Vol. 30 No. 1, pp. 21-27. 
Sheaff, R., Sherriff, I. and Hennessy, C. H. (2018), "Evaluating a dementia learning community: exploratory study and research implications", BMC Health Services Research, Vol. 18 No. 1, p. 83 .

Tamjidyamcholo, A., Baba, M. S. B., Tamjid, H. and Gholipour, R. (2013), "Information security: professional perceptions of knowledge-sharing intention under self-efficacy, trust, reciprocity, and shared-language”, Computers \& Education, Vol. 68, pp. 223-232.

Tasselli, S. (2015), "Social networks and inter-professional knowledge transfer: the case of healthcare professionals", Organization Studies, Vol. 36 No. 7, pp. 841-872.

Tsai, W. (2002), “Social structure of 'coopetition' within a multiunit organization: coordination, competition, and intraorganizational knowledge sharing", Organization Science, Vol. 13 No. 2, pp. 179-190.

Tsay, C. H., Lin, T., Yoon, J. and Huang, C. (2014), "Knowledge withholding intentions in teams: the roles of normative conformity, affective bonding, rational choice and social cognition”, Decision Support Systems, Vol. 67, pp. 53-65.

Tseng, F. and Kuo, F. (2014), “A study of social participation and knowledge sharing in the teachers' online professional community of practice", Computers \& Education, Vol. 72, pp. $37-47$.

Wasko, M. M. and Faraj, S. (2000), ""It is what one does": why people participate and help others in electronic communities of practice", The Journal of Strategic Information Systems, Vol. 9 Nos 2/3, pp. 155-173.

Wenger, E. (2010), "Communities of practice and social learning systems: the career of a concept", in Chris, B. (Ed), Social Learning Systems and Communities of Practice, Springer, London, pp. 179-198

Wenger, E., McDermott, R. and Snyder, W. M. (2002), Cultivating Communities of Practice-, Harvard Business School Press, Boston. 
Wood, R. and Bandura, A. (1989), "Social cognitive theory of organizational management", Academy of Management Review, Vol. 14 No. 3, pp. 361-384.

Zhang, Y., Fang, Y., Wei, K. and Chen, H. (2010), “Exploring the role of psychological safety in promoting the intention to continue sharing knowledge in virtual communities", International Journal of Information Management, Vol. 30 No. 5, pp. 425-436. 